\title{
Analysis of the Function of Elder Education to Continue Socialization of the Elderly
}

\author{
Zhang Xichen ${ }^{1}$ and Li Mengnan ${ }^{2}$ \\ Dept. of Humanities and Social Sciences, ShangHai Vocational College of Science \\ and Technology, China \\ 1xichenzh3389@163.com,239678956@qq.com
}

\begin{abstract}
In the city, more and more elderly people participate in the education of the elderly. This has become a social fact, and many elderly people are reluctant to quit studying once they participate. This shows that education for the elderly has become an important part in the life of the elderly. From the perspective of sociology, this study takes Elderly College as a case to investigate and analyze the functions of the elder college in terms of knowledge transfer, social adaptation, social participation, social interaction, intergenerational relationship, etc. The various studies and participation of the elderly in the geriatric university can avoid social discomfort caused by factors such as retirement and empty nest, and play an important role in continuing socialization of the elderly.
\end{abstract}

Keywords: Elderly, Elderly education, Continued socialization, Function

\section{Introduction}

What is the significance of elderly education to the life of the elderly? Understanding this issue helps to clarify that the society's participation in elderly education is simply to pass the boring time and other wrong understandings to encourage more old people to participate in elderly education. This research tries to explore the development and function of elderly education from the perspective of sociology and introduce the concept of socialization [1].

\section{Related works}

\subsection{Elderly education}

There are broad and narrow senses of senior education. Broad sense education for the elderly refers to activities that promote the knowledge, skills, physical and mental health of the elderly, and change the ideological awareness of the elderly.

For example, the broad sense of elderly education that can help the elderly to increase puzzles, health and mind, such as television, radio, newspapers, audio-visual, etc.

Elderly education in the narrow sense refers to education in elderly schools, which means that educators can achieve a comprehensive, harmonious and active development activities by exerting a purposeful, planned and organized influence on the physical and mental of the elderly learners according to the requirements of society and elderly learners. Including

Article history:

Received (February 15, 2020), Review Result (March 21, 2020), Accepted (April 30, 2020) 
elderly college, elderly schools, and educational institutions that absorb the learning of the elderly organized by relevant administrative departments, agencies, enterprises, undertakings, social groups, communities, and other organizations in various regions [2][3][4].

\subsection{Continuous socialization}

The continuous socialization means that individuals progress on the basis of basic socialization, such as proficient use of basic life skills, consciously abide by social behavior norms, and gradually adjust social relations; while constantly learning new knowledge, new skills, taking on new social roles and establishing new social relationships [5][6].

The continuous socialization of the elderly is the final stage of the continued socialization of adults. Its main role is to enable the elderly to adapt to the changing requirements of daily social life, interact normally with other members of the society, arrange their lives according to the new social norms, and to meet the life needs of themselves and their families.

\section{Design}

\subsection{Selected samples}

Questionnaire survey scope is the students of Elderly College. Random cluster sampling was adopted to survey the students in 8 classes. A total of 252 questionnaires were distributed and 248 were recovered, with a recovery rate of $98 \%$.

\section{2. characteristics of samples}

(1) Gender: among the old students surveyed, 60 were male, accounting for 24\%; 188 were female, accounting for $76 \%$;

(2) Age distribution: age under 59, 60-69, 70-79, 80. The above ratios are 30.2\%, 45.8\%, $21.2 \%$, and $2.8 \%$ respectively;

(3) Education distribution: $15.4 \%$ below junior high school, $416 \%$ from high school education, $23.9 \%$ from junior college, and $19.1 \%$ from university and above;

(4) Occupation Structure: The pre-retirement career structure is dominated by education, professional and technical personnel, and cadres, accounting for $84.3 \%$, while the proportion of ordinary employees and service personnel is relatively small, accounting for $15.7 \%$.

(5) Economic status after retirement: income below 100 dollars Accounted for 15.3\%, 48.8\% for $801-1200$ yuan, $27.1 \%$ for 1201-2000 yuan, and 8.9\% for more than 2001 yuan.

The characteristics of the sample are basically consistent with the overall characteristics of the student, and have a certain representative.

\subsection{Questionnaire design}

The content of the questionnaire is divided into: basic personal situation, learning situation, family relationship situation, community participation in social activities, health status, etc. Each part is divided into several indicators. Use these indicators to reflect the impact of elderly college on the lives of the elderly.

\section{Analysis}


This research mainly analyzes from the aspects of adapting to new changes in social life, social participation, social role change, social interaction, family relations, and collective life reconstruction.

\subsection{Adaptation to new changes in social life}

With the development of production and science and technology, people's lifestyles are constantly changing. If a person cannot adapt to a new lifestyle in time, it will affect family harmony, interpersonal relationships, and social participation. Many elderly people have realized this problem and have chosen to study in elderly college. It can be seen from the research. The following table is a survey about the purpose of the elderly coming to study in elderly college, as shown in [Table 1].

Table 1. Learning purpose of elderly students $(\mathrm{N}=248)$

\begin{tabular}{|c|c|c|}
\hline Learning purpose & Person-time & $\%$ \\
\hline Growth knowledge and improve self-quality & 309 & 41.05 \\
\hline Health and longevity & 91 & 12.16 \\
\hline More friend & 80 & 10.53 \\
\hline Spiritual needs & 70 & 9.26 \\
\hline Leisure and entertainment & 57 & 7.48 \\
\hline Live well & 45 & 6.02 \\
\hline Dreams & 27 & 3.61 \\
\hline Pass time & 20 & 2.74 \\
\hline Reflect own value & 18 & 2.32 \\
\hline Serve as an example for grandchildren & 17 & 2.26 \\
\hline Serve society & 13 & 1.68 \\
\hline Other & 6 & 0.89 \\
\hline Total & 753 & 100 \\
\hline
\end{tabular}

It can be seen from [Table 1] that among the learning objectives of the elderly, increasing knowledge and improving quality account for $45.05 \%$.

One of the significant differences between traditional society and modern society is the understanding of educational value. In the traditional society, science and technology are backward and developing slowly. As a symbol of experience, the elderly are in an authoritative position in the family and society. Education is almost irrelevant to the elderly. In modern society, with the rapid development of science and technology, the original experience has not been able to meet the needs of the society, and the updating speed of knowledge is faster and faster, which makes the elderly fall behind the young people in front of the new technology. As an individual member of the society, the elderly should understand the great changes of people's ideas and behaviors brought by social changes in breadth, and learn to adapt to the high-tech society. To survive in the meeting and change the traditional way of life, we used to depend on the supplement of new knowledge and the development of intelligence. The elderly college has become an important platform for imparting new knowledge. Because the lectures of the elderly college are completely aimed at the elderly 
and are taught in a way suitable for the elderly, they are also easy to be accepted by the elderly.

\subsection{Expansion of participation space}

The theory of social exchange believes that everyone has self-demand and resource capital different from others, and social interaction is the act of satisfying self-demand through resource exchange.

People always get the most benefits with the least cost. According to the exchange theory, the fundamental reason for the decline in the status of the elderly is the lack of exchangeable resources and value [7]. The elderly collage could provide the chance to learn new knowledge for the elderly, and maintains that it still has exchangeable value. And these resources are obtained through studying in senior universities. This exchange is not only reflected in the communication between individuals, but also in the relationship between individuals and society. Elderly students use all kinds of knowledge learned in elderly college to actively participate in community activities and social activities, many people are the backbones in the community. We can look at several survey data from [Table 2].

Table 2. Statistics of participation in community activities and social activities $(\mathrm{N}=248)$

\begin{tabular}{|c|c|}
\hline Project & Frequency(\%) \\
\hline Frequently participate & 25.46 \\
\hline participate & 50.62 \\
\hline Rarely never & 23.92 \\
\hline Totle & 100 \\
\hline
\end{tabular}

Table 3. Statistics of the roles played in community activities and social activities $(\mathrm{N}=248)$

\begin{tabular}{|c|c|}
\hline Project & Frequency $(\%)$ \\
\hline Leadership & 1.53 \\
\hline Guidance & 21.84 \\
\hline Participants & 76.63 \\
\hline Totle & 100 \\
\hline
\end{tabular}

From the above data, it can be seen that $76.08 \%$ of the elderly college students surveyed "frequently participate" and "participate" in community and social activities, of which nearly one quarter have assumed leadership, guidance roles.

Many elderly students have learned relevant knowledge in senior universities that they can play an active role in the community. The community is the main activity place for the elderly in addition to the family. The active role of the elderly in the community plays a role in their better integration into the community. At the same time, older students use the knowledge and skills learned in elderly college to serve the community. In this way, more elderly who do not have the conditions to participate in elderly college education can also enjoy the fruits of social development. The social participation of the elderly is not limited to the community. More and more elderly people have entered the society and are continuously participating in social activities. In the continuous participation, they have rediscovered their position in the society. 
Activity theory believed that there is a satisfactory activity between activities and social relations, which can enable individuals to maintain self-esteem and gain the respect of others. The more sources of non-mandatory roles played by the elderly in the old age, the less likely they will be depressed by the loss of mandatory roles. In adulthood, these mandatory roles are usually placed first [8]. According to the theory of activity, the elderly can make them feel that although they are retired, they are still useful to the society, even if they are retired.

\subsection{Realization of role change}

Adapting and realizing the social role change from middle age to old age is an important issue in old age life. Just as people in childhood have to learn how to grow up and mature, so people in old age have to learn how to adapt to older life. With the increase of age, many changes have taken place in the lives of the elderly. One of the important changes is the loss or weakening of some roles and activities, especially those roles that people are used to taking on and the activities that they have been engaged in for a long time.

An important response from this is that this part of the society or the family is getting older, the social role is getting weaker, and the value of the individual is gradually lost.

The provisions of the national policy and the judgment of others are like a label attached to the elderly, which not only makes others have an incorrect evaluation of the elderly, but also causes some elderly people to feel that the society 's views and practices on themselves are not as good as those of other age groups. This situation prompts some old people to produce negative self-suggestions and attribution biases, such as "I am really old and not useful" and other negative thoughts. As a result, his own mood swings, depression, personality variation, and indifference of interest. Some elderly people retire after a period of time, memory loss, weakened exercise ability, slow response to behavior or physical condition is rapidly weakened, and life expectancy is continuously reduced. However, the number of people who are afraid of getting older increases. This contradiction can be traced to the lack of meaningful roles for individuals in their later life.

Although the leisure time to replace work is justifiable, for the elderly, there is a reality that cannot be easily treated. In the investigation, the author found that a part of the students of the elderly college had appeared in a state of irritability and depression just after retiring. This reflects that the elderly has just left the work, lost the role of the original worker, and are not well adapted to the new social role. Entering the elderly college makes the elderly realize that although they have retired, there are still things to do and they are still useful. They won't be disheartened by the loss of past roles, because there are new and meaningful roles to replace.

\section{Conclusion}

Through empirical investigations, it can be seen that the significance of the elderly university is not only to impart knowledge or skills to the elderly, but more importantly, to provide the elderly with various possibilities of individual social development, that is, the opportunities for the elderly to develop themselves. The space, the supporting point of development, the elderly college serves as an indispensable social support system for the elders' self-development.

Many elderly people are afraid to retire, except because retirement means a reduction in economic income and a decline in living standards. A more important reason is that retirement means the end of social life. Some of the social relationships that were originally 
established on the basis of working relationships no longer exist. People have lost their original relationship with colleagues, lost their respected status, and become non-essential in society. This is more worrying for the elderly than economic factors, because with the improvement of the social security system, the pension of the elderly may increase year by year to meet the needs, but the security system is powerless for the latter.

The social support from the elderly college not only effectively compensated the "partial vacancies in social support" of the elderly due to retirement, but also enabled the elderly to find a new position in the society during this supportive development process. It is undoubtedly of great significance for the elderly to establish a correct self-awareness, smoothly realize the role change, and successfully continue to socialize.

\section{References}

[1] Li Wang, Jianqiang Sun, Sisi Chen, "Research on the Development Strategy of Senior Life Enrichment through Education and the Elderly Education in China," Proceedings of the 2017 International Conference on Economic Development and Education Management (ICEDEM 2017), (2017) DOI: 10.2991/icedem17.2017.48

[2] Chin-Ju Chiu, Chia-Wen Liu, "Understanding Older Adult's Technology Adoption and Withdrawal for Elderly Care and Education: Mixed Method Analysis from National Survey," vol.19, no.11, (2017) DOI: 10.2196/jmir.7401

[3] Duke Appiah and Richard N. Baumgartner, "The Influence of Education and Apolipoprotein $\varepsilon 4$ on Mortality in Community-Dwelling Elderly Men and Women," vol.2018, article ID. 6037058, (2018) DOI: $10.1155 / 2018 / 6037058$

[4] Zhao Xiajin, Tom Plocher, Liana Kiff, "Touch Screen User Interfaces for Older Adults: Button Size and Spacing," International Conference on Universal Access in Human-Computer Interaction, pp.933-941, (2007) DOI: https://doi.org/10.1007/978-3-540-73279-2_104

[5] Dianati, M., Azizi-Fini I., Oghalaee Z., Gilasi H. and Savari F., "The impacts of nursing staff education on perceived abuse among hospitalized elderly people: A field trial,” Nursing and Midwifery Studies, vol.8, no.3, pp.149-154, (2019)

[6] Abah George Ohubuenyi, Ezema, Victor Sunday and Favour Mkpoikanke Out, "Challenges Affecting the Implementation of the Universal Basic Education Programme: Philosophical Implication for Infusion of Information and Communication Technology", International Journal of Education and Learning, NADIA, vol.8, no.1, pp.11-20, (2019) DOI:10.33832/ijel.2019.8.1.02.

[7] Li Xueshu, "Reflection on the Development and Research into Elderly Education," Comparative Education Review, vol.36, no.11, pp.54-68, (2014)

[8] Cheng Meng and Han Buxin, "Relationship between sense of control and mental health of senior college students," Chinese Journal of Gerontology, vol.39, no.2, pp.473-478, (2019) DOI: 10.3969/j.issn.10059202.2019.02.071 